\title{
Glutamic Acid Decarboxylase 1 Measurement
}

National Cancer Institute

\section{Source}

National Cancer Institute. Glutamic Acid Decarboxylase 1 Measurement. NCI Thesaurus.

Code C82015.

The determination of the amount of glutamic acid decarboxylase 1 present in a sample. 